\title{
KARAKTERISTIK KUANTITATIF DAN KUALITATIF KAMBING DAN DOMBA SEBAGAI HEWAN QURBAN DI MITRA TANI FARM
}

\section{THE QUANTITATIVE AND QUALITATIVE CHARACTERISTICS OF SHEEP AND GOATS QURBAN IN THE MITRA TANI FARM}

\author{
Komariah*, Dwi Joko Setyono, dan Aslimah \\ Departemen IImu Produksi dan Teknologi Peternakan, Fakultas Peternakan, Institut Pertanian Bogor, \\ Bogor, 16680
}

Submitted: 12 December 2014, Accepted: 26 February 2015

\begin{abstract}
INTISARI
Penelitian bertujuan mempelajari pilihan konsumen dari berbagai wilayah terhadap jenis ternak qurban, karakteristik kuantitatif dan kualitatif kambing dan domba qurban di Mitra Tani Farm dan mempelajari kriteria ternak penentu konsumen hewan qurban. Sampel ternak dipilih dengan menggunakan metode incidental sampling. Sampel yang diamati sebanyak 83 ekor kambing Jawarandu, 37 ekor domba Garut, 25 ekor domba Ekor Tipis dan 35 ekor domba Ekor Gemuk, semuanya berjenis kelamin jantan. Peubah yang diamati yaitu sifat kuantitatif meliputi bobot badan, lingkar dada, panjang badan dan umur ternak. Sifat kualitatif, meliputi ada tidaknya tanduk dan warna bulu. Wawancara dilakukan dengan pemilik Mitra Tani Farm beserta 30 konsumen akhir dan 30 pedagang. Uji T digunakan untuk mengetahui ada tidaknya perbedaan ukuran tubuh di antara kambing dan domba qurban. Konsumen Jakarta, Depok dan Tangerang secara nyata $(P<0,05)$ lebih memilih kambing daripada domba, sedangkan konsumen Bogor lebih memilih domba daripada kambing. Konsumen pedagang mempertimbangkan bobot badan (postur) dan harga terlebih dahulu dibandingkan karakteristik lain, sedangkan konsumen akhir membeli ternak didasarkan anggaran yang sudah disiapkan. Analisis korelasi dan regresi digunakan untuk mengetahui hubungan antara bobot badan dengan ukuran tubuh ternak. Analisis preferensi konsumen dilakukan dengan uji khi kuadrat. Hasil penelitian menunjukkan rerata bobot badan kambing Jawarandu, domba Garut, domba Ekor Tipis dan domba Ekor Gemuk sebagai hewan qurban secara berturut-turut yaitu $25,84 \pm 4,54 ; 29,32 \pm 3,61 ; 28,45 \pm 5,54$ dan $28,44 \pm 4,65 \mathrm{~kg}$. Lingkar dada mempunyai nilai korelasi yang lebih tinggi terhadap bobot badan daripada panjang badan. Persentase umur domba qurban yaitu: $57,73 \%$ (lo); $37,11 \%\left(I_{1}\right)$ dan $5,16 \%\left(I_{2}\right)$, sedangkan pada kambing $63,86 \%\left(I_{0}\right) ; 30,12 \%\left(I_{1}\right)$ dan $6,02 \%\left(I_{2}\right)$.Warna bulu dominan pada kambing Jawarandu adalah coklat $(54,22 \%)$, hitam (26,51\%) dan putih $(19,28 \%)$. Keragaman warna bulu domba Garut lebih tinggi dari domba Ekor Tipis dan domba Ekor Gemuk. Domba Ekor Gemuk dan domba Ekor Tipis mempunyai keserupaan frekuensi fenotipik.
\end{abstract}

(Kata kunci: Domba, Kambing, Karakteristik, Mitra Tani Farm, Qurban)

\section{ABSTRACT}

The objective of the present study was to study the qualitative characteristics (wool color, horned) and the quantitative characteristics (body weight, chest circumference, body length, age) of sheep and goats for qurban in the Mitra Tani Farm; and the consumers preferences of choosing the sheep and goat required for 'qurban' event. In total eighty three Jawarandu goats; 16 Garut; 37 Thin-Tailed and 35 FatTailed rams were observed to measure their body weight, chest circumference, body length, age, the present of horn and hair color. Qualitative data was obtained by interviewing the owner and consumers of MT Farm (30 trader and 30 consumers). The data was statistically analysis using, chi-square test, correlation test and $T$ test. The results showed that the consumers from Jakarta, Depok and Tangerang significantly $(P<0.05)$ prefer goats than rams, while the consumers from Bogor, Yogyakarta and Bandung prefer rams than goats. The traders more consider the weight of the body (posture) and the price, while consumers more consider the finance budget. The average body weight of Jawarandu was $25.84 \pm 4.54 \mathrm{~kg}$; Garut, Fat-Tailed and Thin-Tailed rams were $29.32 \pm 3.61,28.45 \pm 5.54$ and $28.44 \pm 4.65 \mathrm{~kg}$ respectively. The chest girth had higher correlation with body weight than body length. The percentage of goats and rams age were $60.56 \%\left(I_{0}\right)$, $33.89 \%\left(I_{1}\right)$ and $5.56 \%\left(I_{2}\right)$. The dominant color of Jawarandu goat were brown $(54.2 \%)$, black $(26.51 \%)$ and white $(19.28 \%)$. The color of Fat-Tailed rams wool more uniform than ThinTailed rams or Garut.

(Key words: Characteristics of Sheep and Goat, Mitra Tani Farm, Qurban)

\footnotetext{
* Korespondensi (corresponding author):

Telp. +62 8179910 166, E-mail: komariah_purjati@yahoo.com
} 


\section{Pendahuluan}

Menjelang hari raya Idul Adha, permintaan ternak qurban di berbagai daerah meningkat pesat jika dibandingkan dengan bulan-bulan lain. Meningkatnya pemahaman umat Islam terhadap qurban dan aqiqah menyebabkan permintaan domba dan atau kambing juga meningkat. Permintaan hewan qurban di Jawa Barat mengalami peningkatan berkisar antara $5 \%$ sampai $10 \%$. Jumlah permintaan domba qurban sebanyak 250.000 ekor (Dinas Peternakan dan Perikanan Propinsi Jawa Barat, 2009). Di Kabupaten Bogor mencapai 27.257 ekor domba dan 7.755 ekor kambing (Dinas Peternakan dan Perikanan Kabupaten Bogor, 2010).

Hal tersebut sangat mungkin akan terjadi secara berulang setiap tahun karena qurban merupakan ibadah yang bersifat sunnah muakkad (sangat dianjurkan) dan dilaksanakan setiap tahun bagi orang Islam yang mampu (Rasyid dan Mahmud, 2011). Dalam pelaksanaannya, seekor ternak harus memiliki kriteria tertentu sebelum dijadikan sebagai hewan qurban. Disunahkan berqurban dengan ternak yang gemuk dan baik. Umurnya harus memenuhi kriteria yang telah ditetapkan oleh syariat, tidak memiliki cacat seperti: salah satu matanya buta, sakit, pincang, kurus, lumpuh, salah satu kakinya terputus, telinganya robek dan lainnya (Muhammad, 2002).

Permintaan kambing dan domba qurban yang tinggi merupakan peluang bisnis yang besar. Peternak, pedagang atau penyedia hewan qurban harus memperhatikan dan mengacu kriteria yang telah disebutkan di atas dalam memenuhi permintaan. Mitra Tani Farm merupakan supplier dan penyedia kambing-domba qurban dengan konsumen yang menyebar di beberapa daerah seperti Jakarta, Bogor, Depok, Tangerang dan kota lainnya, sehingga perlu dilakukan penelitian tentang karakteristik kambing-domba qurban yang ada.

Penelitian ini dilakukan dengan tujuan untuk mempelajari karakteristik kuantitatif (bobot badan, lingkar dada, panjang badan, umur) dan kualitatif (warna bulu, sifat pertandukan) kambing dan domba qurban di Mitra Tani Farm, mempelajari preferensi (kesukaan) konsumen terhadap jenis ternak qurban antar berbagai wilayah dan mempelajari kriteria fisik (umur, bobot badan, warna bulu, sifat pertandukan). Manfaat penelitian diharapkan dapat membantu dalam memilih kambing dan domba qurban antara pedagang dengan konsumen akhir.

\section{Materi dan Metode}

\section{Materi}

Penelitian ini dilaksanakan di Mitra Tani Farm Desa Tegal Waru RT 04/ RW 05, Kecamatan Ciampea, Kabupaten Bogor, Jawa Barat. Pengumpulan data primer dilakukan menjelang hari raya Idul Adha selama tiga bulan. Materi yang digunakan dalam penelitian ini adalah kambing dan domba yang sudah dibeli konsumen, terdiri dari kambing Jawarandu (KJR) yang kemudian disebut sebagai kambing Jawa, domba Garut (DG) dan domba Ekor Tipis (DET) yang kemudian disebut domba tanduk, serta domba Ekor Gemuk (DEG) yang disebut sebagai domba Gibas. Sampel yang diamati sebanyak 83 ekor kambing Jawarandu (umur $\mathrm{l}_{0}=53$ ekor, $\mathrm{l}_{1}=25$ ekor, $\mathrm{l}_{2}=5$ ekor); 16 ekor domba Garut (umur $\mathrm{I}_{0}=22$ ekor, $\mathrm{I}_{1}=13$ ekor, $\mathrm{I}_{2}=2$ ekor); 37 ekor domba Ekor Tipis (umur $I_{0}=10$ ekor, $I_{1}=12$ ekor, $I_{2}=3$ ekor) dan 35 ekor domba Ekor Gemuk (umur $I_{0}=24$ ekor, $l_{1}=11$ ekor), berjenis kelamin jantan. Io adalah umur 6-12 bulan, $I_{1}$ umur $13-18$ bulan, $I_{2}$ umur $19-30$ bulan. Peralatan yang digunakan adalah kamera, tongkat ukur dan pita ukur.

\section{Metode}

Data yang dikumpulkan adalah data primer dan sekunder. Data primer diperoleh dengan cara mengukur, mengamati karakteristik ternak, dan wawancara. Karakteristik kuantitatif meliputi: bobot badan, panjang badan, lingkar dada dan umur ternak. Karakteristik kualitatif meliputi karakteristik tanduk dan warna bulu atau wool. Wawancara dilakukan dengan pemilik MT Farm dan 60 konsumen qurban (30 konsumen akhir dan 30 pedagang) di MT Farm. Sampel ternak dipilih dengan menggunakan metode incidental sampling, yaitu teknik penentuan sampel berdasarkan kebetulan. Ternak yang secara incidental ditemui digunakan sebagai sampel. Data sekunder berasal dari rekapitulasi MT Farm yaitu data bobot badan, total penjualan ternak qurban dan asal pembeli.

Pengamatan kualitatif domba meliputi tipe daun telinga, warna bulu dan ada tidaknya tanduk. Daun telinga dibagi dalam dua kelompok yaitu (i) pendek (rumpung), yaitu bentuk daun telinga menguncup atau menggulung, berukuran pendek, kecil, daun 
telinga tidak tampak jelas dan tampak hampir seperti tidak berdaun telinga; (ii) medium (daun hiris), yaitu bentuk daun telinga lebar dan panjang, ujung telinga tidak runcing (bulat) dan lubang telinga tampak jelas.

Pengamatan kualitatif kambing yaitu bentuk daun telinga dibagi dalam dua kelompok yaitu: pendek-tegak dan panjanglebar-terkulai. Kambing dengan telinga pendek-tegak adalah kambing Kacang, sedangkan yang bertelinga panjang-lebarterkulai adalah kambing Jawarandu. Pendugaan umur domba dan kambing berdasarkan pergantian gigi seri. Warna bulu didasarkan pada kelompok warna dominan. Warna dominan adalah warna yang paling banyak persentase warna tubuh (diperkirakan di atas 60\%), dikelompokkan ke dalam 3 macam, yaitu: putih $(\mathrm{P})$, hitam $(\mathrm{H})$ dan coklat (C).

Panjang badan (PB) adalah jarak garis lurus dari tepi tulang processus spinosus sampai os ischium; pengukuran menggunakan tongkat ukur (cm). Lingkar dada (LD) diukur melingkar rongga dada di belakang sendi bahu; pengukuran menggunakan pita ukur.

\section{Analisis data}

Analisis statistik. Analisis statistik digunakan untuk membandingkan bobot badan, lingkar dada dan panjang badan kambing dan domba pada bangsa yang berbeda dengan menggunakan Rancangan Acak Kelompok berdasarkan umur menurut Walpole (1993).

Analisis korelasi. Analisis korelasi digunakan untuk melihat korelasi antara bobot badan dengan panjang badan dan lingkar dada ternak pada umur yang berbeda. Analisis korelasi diolah dengan perangkat lunak (software) MINITAB 15 dengan tingkat kepercayaan $95 \%$.
Analisis khi kuadrat. Analisis khi kuadrat digunakan untuk menguji dua hal, pertama adalah untuk menguji ada tidaknya perbedaan antara jumlah dan jenis ternak yang terjual ke wilayah satu dengan wilayah lainnya. Kedua, menguji ada tidaknya perbedaan antara jenis konsumen dengan karakteristik ternak (bobot badan, umur, warna bulu dan ada tidaknya tanduk) yang dibeli. Analisis khi kuadrat diolah dengan program SPSS (Statistical Product for the Social Science) dengan tingkat kepercayaan $95 \%$.

Uji t. Uji t digunakan untuk menguji tiga hal, pertama untuk mengetahui ada tidaknya pengaruh tanduk terhadap harga jual domba. Kedua, mengetahui ada tidaknya perbedaan rerata ukuran tubuh bangsa ternak pada tingkat umur yang berbeda. Uji $t$ diolah dengan program MINITAB 15.

\section{Hasil dan Pembahasan}

Jumlah keseluruhan ternak yang terjual sebanyak 1.748 ekor. Data menunjukkan bahwa konsumen Jakarta dan Bogor mendominasi pembelian kambing dan domba qurban dibandingkan Depok, Tangerang, Bandung dan Yogyakarta. Sebesar 80,22\% kambing terjual ke Jakarta, sedangkan $74,69 \%$ domba tanduk dan 58,08\% Gibas ke Bogor. Hasil uji khi kuadrat menunjukkan bahwa terdapat perbedaan nyata $(P<0,05)$ antara daerah konsumen dengan jenis ternak yang dibeli. Konsumen Jakarta, Depok dan Tangerang secara nyata $(P<0,05)$ lebih memilih kambing daripada domba, sedangkan konsumen Bogor secara nyata $(P<0,05)$ lebih memilih domba (tanduk maupun tidak) daripada kambing. Ternak yang daerah tujuannya ke Bandung dan Yogyakarta, pembelinya adalah lembaga sosial yang kemudian didistribusikan ke daerah tersebut. Dalam pembeliannya, lembaga tersebut tidak

Tabel 1. Penjualan kambing dan domba qurban MT Farm ke beberapa wilayah konsumen (the goats and sheep market areas of MT Farm)

\begin{tabular}{lcccc}
\hline \hline $\begin{array}{c}\text { Wilayah pasar } \\
\text { (market areas) }\end{array}$ & $\begin{array}{c}\text { Kambing } \\
\text { (goat) }\end{array}$ & $\begin{array}{c}\text { Domba Tanduk } \\
\text { (horned sheep) }\end{array}$ & $\begin{array}{c}\text { Domba Gibas } \\
\text { (polled sheep) }\end{array}$ & $\begin{array}{c}\text { Total } \\
\text { (sum) }\end{array}$ \\
\hline Jakarta & 803 & 4 & 61 & 868 \\
Bogor & 84 & 239 & 248 & 571 \\
Depok & 44 & 1 & 2 & 47 \\
Tangerang & 64 & 3 & 1 & 68 \\
Bandung & 6 & 15 & 0 & 21 \\
Yogyakarta & 0 & 58 & 115 & 173 \\
$\quad$ Total (sum) & 1001 & 320 & 427 & 1748 \\
\hline
\end{tabular}


menyebutkan jenis ternak yang dikehendaki, tetapi disesuaikan dengan dana yang disediakan tanpa mengabaikan syarat yang berlaku seperti umur dan kesehatan. Distribusi ke Yogyakarta dipusatkan di daerah korban bencana gunung merapi.

\section{Karakteristik kuantitatif kambing dan domba qurban}

Bobot badan domba Garut pada penelitian ini lebih rendah dari bobot yang ditetapkan Departemen Pertanian (2011) mengenai rumpun domba Garut yaitu $57,74 \pm 11,9 \mathrm{~kg}$. Perbedaan yang sangat jauh ini kemungkinan domba Garut di MT Farm sudah tidak murni, hasil perkawinan dengan domba-domba lokal lainnya serta umurnya lebih muda.

Rerata bobot badan kambing Jawarandu berbeda sangat nyata $(P<0,01)$ dibandingkan dengan domba Garut dan domba Ekor Gemuk, dan berbeda nyata $(P<0,05)$ dengan domba Ekor Tipis. Hal ini menunjukkan bahwa perbedaan spesies mempengaruhi ukuran atau bobot badan. Secara umum, bobot badan dari domba dan kambing qurban di MT Farm berkisar 21,3$32,93 \mathrm{~kg}$. Rerata bobot badan domba maupun kambing qurban yang tidak mencapai $35 \mathrm{~kg}$ atau lebih besar dari itu tidak berarti bahwa sulit mendapatkannya, tetapi dalam hal ini MT Farm menyesuaikan dengan permintaan dan daya beli konsumen. Hadist tentang qurban menganjurkan untuk memilih ternak yang gemuk (Rasyid dan Mahmud, 2011). Pada umumnya konsumen akan memilih ternak yang sehat dengan harga terjangkau serta memenuhi kriteria hewan qurban.

\section{Lingkar dada dan panjang badan}

Ukuran panjang badan domba tidak berbeda nyata diantara ketika bangsa yang berbeda maupun dalam bangsa yang sama pada kelas yang berbeda. Hal ini menunjukkan bahwa parameter panjang badan dinilai kurang tepat jika digunakan sebagai pedoman untuk mendapatkan domba yang berkelas (berbobot) tinggi.

Secara keseluruhan, adanya perbedaan kelas menunjukkan ukuran lingkar dada yang berbeda sangat nyata $(P<0,01)$ antara domba Garut dan domba Ekor Tipis dengan domba Ekor Gemuk. Ukuran lingkar dada domba pada bangsa yang sama tetapi berbeda kelas juga menunjukkan hasil yang berbeda nyata. Berbeda dengan domba, secara umum adanya perbedaan kelas pada kambing Jawarandu mempunyai ukuran

Tabel 2. Rerata bobot badan kambing dan domba qurban (the average of goats and sheep body weight)

\begin{tabular}{lccc}
\hline \hline \multicolumn{1}{c}{ Jenis ternak (animal) } & Bobot badan $(\mathrm{kg})$ (body weight $(\mathrm{kg}))$ & $\mathrm{n}$ & Kelas (classes) \\
\hline DG & $29,32 \pm 3,61^{\mathrm{a}}$ & 37 & B-D \\
DET & $28,45 \pm 5,54^{\mathrm{a}}$ & 25 & A-E \\
DEG & $28,44 \pm 4,65^{\mathrm{a}}$ & 35 & A-E \\
KJR & $25,84 \pm 4,54^{\mathrm{b}}$ & 83 & A-D \\
$\quad$ Rerata (average) & $27,43 \pm 4,75$ & 180 & A-D \\
\hline
\end{tabular}

$\overline{\mathrm{DG}}=$ domba Garut (Garut rams), DET= domba Ekor Tipis (Thin-Tailed rams), DEG= domba Ekor Gemuk (Fat-Tailed rams), KJR= kambing Jawarandu (Jawarandu goat).

a,b Superskrip yang berbeda pada kolom yang sama menunjukkan hasil sangat beda nyata $(P<0,01)$ (different superscripts at the same column indicate significant differences $(P<0.01))$.

Tabel 3. Rerata ukuran tubuh domba qurban (the average of sheep morphometri's)

\begin{tabular}{|c|c|c|c|}
\hline Parameter ukuran tubuh (morphometri's) & DG (cm) & DET $(\mathrm{cm})$ & DEG (cm) \\
\hline \multicolumn{4}{|l|}{ Lingkar dada (chest circumference) } \\
\hline A-C & $68,30 \pm 4,46^{a}$ & $67,12 \pm 4,37^{a}$ & $63,52 \pm 3,90^{b}$ \\
\hline $\mathrm{D}-\mathrm{F}$ & $74,35 \pm 6,04^{a}$ & $74,13 \pm 2,30^{a}$ & $70,60 \pm 2,80^{b}$ \\
\hline Rerata umum (general average) & $69,93 \pm 5,56^{a}$ & $69,36 \pm 5,04^{a}$ & $65,54 \pm 4,83^{b}$ \\
\hline \multicolumn{4}{|l|}{ Panjang badan (body length) } \\
\hline $\mathrm{A}-\mathrm{C}$ & $54,30 \pm 4,34$ & $53,74 \pm 4,48$ & $52,58 \pm 3,17$ \\
\hline $\mathrm{D}-\mathrm{F}$ & $57,45 \pm 5,31$ & $56,56 \pm 4,18$ & $55,30 \pm 2,30$ \\
\hline Rerata umum (general average) & $55,15 \pm 4,76$ & $54,64 \pm 4,50$ & $53,36 \pm 3,17$ \\
\hline \multicolumn{4}{|c|}{$\begin{array}{l}\mathrm{DG}=\text { domba Garut (Garut rams), DET= domba Ekor Tipis (Thin-Tailed rams), DEG= domba Ekor Gemuk (Fat-Tailed } \\
\text { rams). }\end{array}$} \\
\hline a,b Superskrip yang berbeda pada baris yang sama & & & \\
\hline
\end{tabular}


Tabel 4. Rerata ukuran tubuh kambing qurban (the average of goat morphometri's)

\begin{tabular}{cccccc}
\hline \hline \multirow{2}{*}{$\begin{array}{c}\text { Ukuran tubuh } \\
\text { (morphometri) }\end{array}$} & $\begin{array}{c}\text { Berdasarkan keseluruhan } \\
\text { data (total data) }\end{array}$ & $\mathrm{A}(\mathrm{n}=37)$ & $\mathrm{B}(\mathrm{n}=16)$ & $\mathrm{C}(\mathrm{n}=15)$ & $\mathrm{D}-\mathrm{F}(\mathrm{n}=15)$ \\
\cline { 3 - 6 } & $63,92 \pm 6,24$ & $59,91 \pm 4,06^{\mathrm{a}}$ & $63,47 \pm 2,35^{\mathrm{b}}$ & $67,03 \pm 3,77^{\mathrm{c}}$ & $73,25 \pm 6,36^{\mathrm{d}}$ \\
LD $(\mathrm{cm})$ & $53,22 \pm 6,17$ & $49,82 \pm 4,49^{\mathrm{a}}$ & $52,34 \pm 2,80^{\mathrm{b}}$ & $55,43 \pm 5,70^{\mathrm{b}}$ & $61,67 \pm 5,38^{\mathrm{c}}$ \\
\hline
\end{tabular}

$\mathrm{LD}=$ lingkar dada (chest circumference), $\mathrm{PB}=$ panjang badan (body length).

a,b,c,d Superskrip yang berbeda pada baris yang sama menunjukkan perbedaan yang sangat nyata $(P<0,01)($ different superscripts at the same row indicate significant differences $(P<0.01))$.

lingkar dada dan panjang badan yang berbeda. Setiap komponen tubuh mempunyai kecepatan pertumbuhan dan perkembangan yang berbeda karena pengaruh genetik maupun lingkungan (Doho, 1994).

\section{Analisis regresi dan korelasi antara ukuran tubuh dengan bobot badan kambing dan domba qurban}

Lingkar dada dan panjang badan memiliki korelasi atau hubungan erat dengan bobot badan pada penelitian Doho (1994). Tabel 5 memperlihatkan bahwa nilai korelasi lingkar dada dengan bobot badan lebih besar daripada panjang badan dengan bobot badan. Hasil serupa juga diperoleh pada penelitian yang dilakukan oleh Suswati (2010). Lingkar dada adalah bagian tubuh yang mengalami perbesaran ke arah samping. Pertambahan bobot badan ternak menyebabkan hewan bertambah besar dan diikuti dengan pertambahan dan perkembangan otot yang ada di daerah dada sehingga ukuran lingkar dada semakin meningkat (Doho, 1994).

Ukuran lingkar dada tidak dipengaruhi oleh posisi berdiri ternak (Suswati, 2010). Dari
Tabel 5 dapat dikatakan bahwa nilai ketepatan $\mathrm{R}^{2}$ (adj) yang dihasilkan pada grafik kuadratik antara bobot badan dengan lingkar dada domba Garut lebih tinggi (63,6\%) daripada domba Ekor Tipis (61,9\%), sedangkan pada domba Ekor Gemuk nilai ketepatan $\mathrm{R}^{2}$ grafik pangkat tiga lebih tinggi (76\%) daripada $R^{2}$ grafik pangkat tiga kambing Jawarandu (69,8\%). Hal ini menunjukkan bahwa model grafik kuadratik lebih tepat digunakan untuk menggambarkan hubungan bobot badan (y) terhadap lingkar dada (x) pada domba Garut dan domba Ekor Tipis, sedangkan model grafik pangkat tiga lebih tepat digunakan untuk menggambarkan hubungan bobot badan (y) terhadap lingkar dada (x) pada domba Ekor Gemuk dan kambing Jawarandu karena nilai ketepatan $\mathrm{R}^{2}$ (adj) yang dihasilkan lebih besar dibandingkan nilai $\mathrm{R}^{2}$ (adj) pada grafik lainnya sehingga nilai erornya akan lebih rendah.

Bentuk persamaan yang tidak linier antara bobot badan (y) dengan lingkar dada (x) menunjukkan bahwa pola pertambahan bobot badan antar waktu sehubungan dengan perubahan lingkar dada adalah tidak tetap. Bobot badan rendah pada permulaan, naik

Tabel 5. Analisis regresi dan korelasi antara ukuran tubuh dengan bobot badan pada domba dan kambing qurban

(the regression and correlation analysis of sheep and goat morphometri and body weight's)

\begin{tabular}{|c|c|c|c|c|}
\hline Parameter & $\begin{array}{l}\text { Bangsa } \\
\text { (breeds) }\end{array}$ & Persamaan regresi (regression similarity) & $\begin{array}{c}\text { Korelasi (correlation) } \\
\text { (r) }\end{array}$ & $\begin{array}{c}\mathrm{R}^{2}(\operatorname{adj}) \\
(\%)\end{array}$ \\
\hline \multirow[t]{4}{*}{ LD-BB } & DG & $y=104-2,52 x+0,021 x^{2}$ & $0,746^{* *}$ & 63,6 \\
\hline & DET & $y=345,6-10,13 x+0,080 x^{2}$ & $0,708^{* *}$ & 61,9 \\
\hline & DEG & $y=2.460-111,1 x+1,67 x^{2}-0,008 x^{3}$ & $0,845^{\star *}$ & 76 \\
\hline & KJR & $y=533,3-23,96 x+0,37 x^{2}-0,002 x^{3}$ & $0,812^{\star *}$ & 69,8 \\
\hline \multirow[t]{4}{*}{ PB-BB } & DG & $y=0,353 x+9,85$ & $0,466^{\star *}$ & 19,5 \\
\hline & DET & $y=0,710 x-10,3$ & $0,577^{* *}$ & 30,4 \\
\hline & DEG & $y=0,718 x-9,9$ & $0,490^{* *}$ & 21,7 \\
\hline & KJR & $y=0,585 x-5.27$ & $0.794^{* *}$ & 62,7 \\
\hline
\end{tabular}


pada tahap pertengahan dan turun ketika di akhir siklus hidupnya. Hal ini berbeda dengan hubungan antara bobot badan dengan panjang badan. Nilai ketepatan $\mathrm{R}^{2}$ (adj) yang dihasilkan pada grafik linier antara bobot badan dengan panjang badan lebih besar daripada yang dihasilkan pada grafik non linier, sehingga model grafik linier lebih tepat digunakan untuk menggambarkan hubungan bobot badan (y) terhadap panjang badan (x).

Umur ternak qurban. Data yang terlihat pada Tabel 6 menunjukkan bahwa $63,86 \%$ kambing qurban berumur kurang dari satu tahun. Berdasarkan syariah maka sebanyak 63,86\% kambing tersebut belum sah dijadikan qurban karena syarat umur kambing yang akan dijadikan qurban adalah minimal genap berumur 1 tahun, sedangkan domba minimal genap berumur enam bulan (Muhammad, 2002). Banyaknya kambing yang belum cukup umur tersebut tidak berarti bahwa MT Farm tidak memperhatikan faktor umur ternak qurban, tetapi hal tersebut adalah pilihan konsumen sendiri. Tingginya permintaan kambing qurban yang tidak setara dengan jumlah kambing cukup umur membuat konsumen memilih berqurban dengan kambing apa adanya daripada tidak berqurban. Oleh karena itu, diperlukan sistem produksi yang tepat dalam rangka menyediakan ternak qurban khususnya kambing sehingga permintaan kambing qurban yang tinggi dapat didukung dengan persyaratan yang sesuai syariah tanpa melupakan persediaan ternak pejantan unggul. Sistem yang mungkin dapat dilakukan adalah melakukan konsep pemeliharaan yang ter- pusat di suatu daerah atau kawasan yang dilengkapi dengan sistem seleksi yang baik sehingga pejantan dengan sifat-sifat yang unggul dapat diselamatkan untuk dijadikan pemacek.

Penetapan syarat umur ternak qurban pasti mengandung hikmah di dalamnya. IImu pengetahuan menilai bahwa salah satu faktor adanya perbedaan syarat umur antara kambing dengan domba yang akan dijadikan qurban mungkin terkait dengan kualitas daging yang akan dihasilkan. Faktor umur merupakan salah satu hal yang menentukan kualitas dan komposisi daging (Soeparno, 2005).

\section{Karakteristik kualitatif kambing dan domba qurban}

Warna bulu. Warna bulu dominan yang terdapat pada domba adalah putih $(P)$ hitam $(\mathrm{H})$ dan coklat $(\mathrm{C})$. Pada Tabel 7 menunjukkan bahwa dari ketiga warna tersebut, warna bulu (P) pada domba memiliki persentase terbesar (45,45-100\%). Warna dominan Domba Garut pada penelitian ini sesuai dengan hasil Riwantoro (2005) yang mendapatkan warna dasar Domba Garut adalah hitam, putih dan coklat. Warna putih dan hitam banyak dijumpai pada Domba Garut jantan tipe daging.

Departemen Pertanian (2011) menjelaskan lebih lanjut bahwa warna tubuh dan kepala dominan domba Garut adalah kombinasi hitam-putih. Dari ketiga bangsa domba yang diamati, tampak bahwa keragaman warna bulu berdasarkan fenotipik pada domba Garut lebih tinggi dari domba

Tabel 6. Persentase umur ternak qurban

(the percentage of animal age)

\begin{tabular}{|c|c|c|c|c|}
\hline \multirow[t]{2}{*}{ Jenis ternak (animal) } & \multicolumn{3}{|c|}{ Umur (ages) } & \multirow[t]{2}{*}{ Jumlah (sum) } \\
\hline & $\mathrm{I}_{0}$ & $\mathrm{l}_{1}$ & $I_{3}$ & \\
\hline Domba (sheep) & $57,73(n=56)$ & $37,11(n=36)$ & $5,16(n=5)$ & $100(n=97)$ \\
\hline Kambing (goats) & $63,86(n=53)$ & $30,12(n=25)$ & $6,02(n=5)$ & $100(n=83)$ \\
\hline
\end{tabular}

Tabel 7. Persentase domba dan kambing qurban berdasarkan warna bulu dominan (the percentage of sheep and goats based on wool colors)

\begin{tabular}{|c|c|c|c|c|}
\hline Jenis ternak (animal) & $\begin{array}{c}\text { Putih (\%) } \\
\text { (white (\%)) }\end{array}$ & $\begin{array}{c}\text { Hitam (\%) } \\
\text { (black (\%)) }\end{array}$ & $\begin{array}{c}\text { Coklat }(\%) \\
(\text { brown }(\%))\end{array}$ & Jumlah (sum) \\
\hline DG & $45,45(n=16)$ & $36,36(n=13)$ & $18,18(n=6)$ & $100(n=37)$ \\
\hline DET & $100(n=25)$ & - & - & $100(n=25)$ \\
\hline DEG & $100(n=35)$ & - & - & $100(n=35)$ \\
\hline KJR & $19,28(n=16)$ & $26,51(n=22)$ & $54,22(n=45)$ & $100(n=83)$ \\
\hline Rerata (average) & $51,11(n=92)$ & $19,44(n=35)$ & $28,33(n=51)$ & $100(n=180)$ \\
\hline
\end{tabular}

$\overline{\mathrm{DG}}=$ domba Garut (Garut rams), DET= domba Ekor Tipis (Thin-Tailed rams), DEG= domba Ekor Gemuk (Fat-Tailed rams), KJR= kambing Jawarandu (Jawarandu goat). 
Ekor Tipis dan domba Ekor Gemuk. Domba Ekor Gemuk dan domba Ekor Tipis mempunyai keserupaan frekuensi fenotipik. Warna bulu domba Ekor Gemuk dan domba Ekor Tipis yang sudah seragam ini dimungkinan warna bulu domba tersebut sudah murni.

Warna bulu dominan yang terdapat pada kambing Jawa adalah hitam $(\mathrm{H})$, coklat (C) dan putih $(P)$. Warna bulu $(H)$ terdiri dari hitam polos dan hitam dengan belang. Kambing Jawarandu dengan warna $(P)$ terdiri dari putih polos dan belang, baik belang hitam maupun coklat. Kambing Jawarandu dengan warna dominan (C) tampak lebih beragam dibandingkan dengan kelompok $(H)$ dan $(P)$, yaitu coklat tua polos, coklat muda polos, coklat dengan belang besar, belang kecil hitam maupun putih, coklat dengan garis punggung hitam. Pola warna pada kambing Jawarandu coklat yang diamati ada tiga macam, yaitu: coklat polos atau coklat dengan hitam, coklat dengan putih atau kombinasi tiga warna tersebut. Hadist tentang qurban menjelaskan bahwa warna bulu ternak qurban yang utama sebaiknya berwarna putih, adapun jika didapati kambing atau domba qurban yang berwarna coklat, hitam atau yang lainnya maka tetap sah selama ternak tersebut sehat, tidak buta atau lumpuh.

Tanduk. Berdasarkan pengamatan didapatkan, $75,57 \%$ kambing dan domba qurban bertanduk, sisanya sebesar $24,43 \%$ tidak bertanduk (Tabel 8). Hadist tentang qurban menjelaskan bahwa domba maupun kambing yang bertanduk lebih utama digunakan sebagai qurban. Hasil uji beda menunjukkan bahwa domba yang bertanduk nyata bernilai jual lebih tinggi daripada yang tidak bertanduk $(P<0,05)$ meskipun bobotnya sama. Tanduk pada seekor ternak merupakan salah satu parameter penilaian penampilan individu ternak (Noor, 2008). Utuh tidaknya tanduk juga dapat mempengaruhi penilaian penampilan ternak. Muhammad (2002) menyatakan bahwa ternak yang terpotong separuh tanduknya atau ada cacat dan tidak bertanduk dinilai makruh untuk dijadikan qurban.

Adanya karakteristik ternak qurban yang disyariatkan pada akhirnya menyebabkan adanya pilihan yang jelas diantara konsumen atau penyedia yang mengetahui dan memahaminya dalam membeli atau menyediakan ternak. Berdasarkan Tabel 9 dapat diketahui bahwa perhatian konsumen qurban terhadap kriteria umur dan warna bulu ternak terlihat rendah dibandingkan dengan bobot badan dan tanduk. Terdapat perbedaan yang nyata $(P<0,05)$ antara pedagang dan konsumen akhir dalam pemilihan kriteria ternak qurban. Pedagang nyata $(P<0,05)$ lebih memilih kriteria bobot badan (postur) daripada kriteria lain, sedangkan konsumen akhir nyata $(P<0,05)$ lebih memilih kriteria tanduk. Konsumen akhir juga membeli berdasarkan anggaran dana yang sudah disiapkan.

Adanya syariat yang menyatakan bahwa domba yang tidak bertanduk hukumnya makruh untuk dijadikan qurban secara tidak langsung memberikan isyarat pentingnya untuk melestarikan bangsa domba yang bertanduk, tetapi tidak berarti juga bahwa tidak penting melestarikan domba yang tidak bertanduk. Melestarikan keduanya adalah penting untuk memenuhi kebutuhan pangan, pertanian dan perkembangan sosial masyarakat di masa kini dan yang akan datang. Berbeda dengan domba yang secara genetik ada yang tidak bertanduk, pada

Tabel 8. Persentase domba dan kambing qurban berdasarkan ada tidaknya tanduk (the percentage of sheep and goats based on horned or polled)

\begin{tabular}{cc}
\hline \hline \multicolumn{1}{c}{ Ada/tidaknya tanduk (horned or polled) } & $\%$ \\
\hline Bertanduk (horned) & $75,57(\mathrm{n}=1.321)$ \\
Tidak bertanduk (polled) & $24,43(\mathrm{n}=427)$ \\
Jumlah (sum) & $100(\mathrm{n}=1.748)$ \\
\hline
\end{tabular}

Tabel 9. Persentase kriteria ternak penentu konsumen qurban (the consumers criteria for animal chosen)

\begin{tabular}{lcc}
\hline \hline \multicolumn{1}{c}{ Kriteria (criteria) } & Pedagang (\%) (traders (\%)) & $\begin{array}{c}\text { Konsumen akhir (\%) } \\
\text { (final consumers (\%)) }\end{array}$ \\
\hline Bobot badan (body weight) & $66,67(\mathrm{n}=20)$ & - \\
Umur (age) & $16,67(\mathrm{n}=5)$ & $6,67(\mathrm{n}=5)$ \\
Warna bulu (wool colors) & $3,3(\mathrm{n}=1)$ & $10(\mathrm{n}=3)$ \\
Tanduk (horned) & $3,3(\mathrm{n}=1)$ & $70(\mathrm{n}=21)$ \\
Tanpa criteria (none criteria) & $10,06(\mathrm{n}=3)$ & $3,3(\mathrm{n}=1)$ \\
\hline
\end{tabular}


semua bangsa kambing ditemukan adanya tanduk meskipun besar atau panjangnya berbeda-beda.

Dengan demikian, ada tidaknya tanduk pada kambing bukanlah suatu pilihan, tetapi yang menjadi pilihan yaitu mengenai bobot atau postur tubuh. Konsumen cenderung memilih kambing yang postur tubuhnya terlihat tinggi atau besar, padahal belum tentu bobotnya besar. Jika demikian, maka konsumen akan memilih kambing Jawarandu daripada kambing Kacang sebagaimana yang sudah terjadi di MT Farm dan pada akhirnya dikhawatirkan populasi kambing Kacang akan menurun. Dengan demikian, diperlukan upaya pengelolaan sumber daya genetik ternak-ternak yang ada.

\section{Kesimpulan}

Karakeristik kuantitatif domba dan kambing untuk hewan qurban di Mitra Tani Farm memiliki bobot badan $25,84 \pm 4,54 \mathrm{~kg}$ untuk kambing. Rerata bobot badan domba Garut, domba Ekor Tipis dan domba Ekor Gemuk secara berturut-turut yaitu 29,32 $\pm 3,61$ $\mathrm{kg}, 28,45 \pm 5,54 \mathrm{~kg}$ dan 28,44 44,65 kg. Lingkar dada kambing atau domba mempunyai nilai korelasi yang lebih tinggi dengan bobot badan daripada panjang badan. Persentase umur kambing dan domba qurban yang ada yaitu $60,56 \%\left(I_{0}\right), 33,89 \%\left(I_{1}\right)$ dan $5,56 \%\left(I_{2}\right)$. Persentase warna bulu dominan pada kambing adalah coklat $(54,22 \%)$, hitam $(26,51 \%)$ dan putih $(19,28 \%)$. Warna coklat lebih beragam dibandingkan dengan warna lainnya. Ternak yang bertanduk nyata bernilai jual lebih tinggi daripada yang tidak bertanduk meskipun bobot badannya sama bahkan lebih tinggi. Konsumen Jakarta, Depok, dan Tangerang lebih memilih kambing daripada domba, sedangkan konsumen Bogor, Bandung dan Yogyakarta nyata lebih memilih domba (tanduk maupun tidak) daripada kambing sebagai hewan qurban. Konsumen dari kalangan pedagang mempertimbangkan bobot badan (postur) dan harga terlebih dahulu dibandingkan karakteristik lain, sedangkan konsumen individu membeli ternak didasarkan atas anggaran dana yang sudah disiapkan.

\section{Daftar Pustaka}

Departemen Pertanian. 2011. Keputusan Menteri Pertanian Nomor: 2914/Kpts/Ot.140/6/2011 tentang Penetapan Rumpun Domba Garut. Departemen Pertanian RI, Jakarta.

Dinas Peternakan dan Perikanan Kabupaten Bogor. 2010. Rekapitulasi Pemotongan Ternak Di Kabupaten Bogor Tahun 2009. Dinas Peternakan dan Perikanan Kabupaten Bogor, Bogor.

Dinas Peternakan dan Perikanan Propinsi Jawa Barat. 2009. Rekapitulasi Pemotongan Ternak Di Propinsi Jawa Barat. Dinas Peternakan dan Perikanan Propinsi Jawa Barat, Bandung.

Doho, S. R. 1994. Parameter fenotipik beberapa sifat kualitatif dan kuantitatif pada domba Ekor Gemuk. Tesis Program Pascasarjana Institut Pertanian Bogor, Bogor.

Muhammad. 2002. Tata Cara Qurban Tuntunan Nabi. Edisi ke-10. Terjemahan: Aris Munandar. Media Hidayah, Yogyakarta.

Noor, R. R. 2008. Genetika Ternak. Cetakan ke-4. Penebar Swadaya, Jakarta.

Rasyid, H. dan A. Mahmud. 2011. Pedoman Qurban Praktis dan Higienis. Pusat Pengkajian dan Pengembangan Islam Jakarta. Koja, Jakarta.

Riwantoro. 2005. Konservasi plasma nutfah domba Garut dan strategi pengembangannya secara berkelanjutan. Disertasi Pascasarjana Institut Pertanian Bogor, Bogor.

Soeparno. 2005. Ilmu dan Teknologi Daging. Cetakan keempat. Gadjah Mada Press, Yogyakarta.

Suswati. 2010. Sifat kualitatitif dan kuantitatif domba qurban pada grade yang berbeda. Skripsi Fakultas Peternakan, Institut Pertanian Bogor, Bogor.

Walpole, R. E. 1993. Introduction to Statistics. $3^{\text {rd }}$ edn. Alih bahasa: Bambang Sumantri. PT Gramedia, Jakarta. 